\title{
FLOW CYTOMETRIC DETECTION OF OXIDATIVE DNA DAMAGE IN FISH SPERMATOZOA EXPOSED TO CADMIUM - SHORT COMMUNICATION
}

\author{
Szabolcs NAGY ${ }^{1 *}$, Balázs KAKASI ${ }^{2}$ and Miklós BERCSÉNYI ${ }^{1}$ \\ ${ }^{1}$ Department of Animal Sciences and Animal Husbandry, Georgikon Faculty, University \\ of Pannonia, Deák F. u. 16, H-8360 Keszthely, Hungary; ${ }^{2}$ Department of Limnology, \\ Institute of Environmental Sciences, University of Pannonia, Veszprém, Hungary
}

(Received 20 April 2015; accepted 28 October 2015)

\begin{abstract}
The aim of the present pilot study was to apply a flow cytometric assay, the so-called OxyDNA test, to determine the level of oxidative DNA damage in fish spermatozoa exposed to different concentrations $(0.01-10,000 \mathrm{mg} / \mathrm{L})$ of cadmium. Milt was collected from three randomly selected Prussian carp (Carassius auratus gibelio) males. Oxidative DNA damage was assessed with the OxyDNA kit and using flow cytometry. The ratio of OxyDNA-positive events increased significantly at higher cadmium concentrations. The results indicate that direct contact of fish spermatozoa with cadmium-polluted water initiates genotoxic damage.
\end{abstract}

Key words: Cadmium, DNA damage, fish sperm, flow cytometry, OxyDNA

Studies on domestic animal species indicated that early embryonic death is often caused by nuclear defects of the fertilising spermatozoa. Abnormalities of sperm chromatin structure can cause disturbances in fertility, pronuclear formation, early embryo quality, and pregnancy outcome. Sperm cells with such defects are able to fertilise oocytes, but embryonic development may be abnormal (Evenson, 1999). The organisation of the sperm chromatin is unique, as histone proteins are eventually replaced by transition proteins and finally by protamines, resulting in an extremely compact, condensed DNA (Dadoune, 1995; Sakkas et al., 1999). Proper condensation may stabilise the DNA and make it less sensitive to oxidative damage; however, mature spermatozoa are not able to repair DNA damage (Olsen et al., 2005).

The presence of DNA strand breaks in spermatozoa can be associated with oxidative stress, heat stress, radiation, or protamine deficiency (Varner, 2008). Due to incomplete protamination the spermatozoa will be more vulnerable to attack by endogenous or exogenous agents such as nucleases, free radicals or mutagens (Oliva, 2006). Sperm cells with such damage seem to be 'normal'

*Corresponding author; E-mail: nagy.szabolcs@georgikon.hu; Phone: 0036 (83) 545-349; Fax: 0036 (83) 545-107 
based on laboratory test results like motility or viability (plasma membrane integrity), but may induce post-fertilisation embryonic failure. As mature spermatozoa are transcriptionally inactive, DNA damage may not be expressed until mitosis at the time of spermatozoon-oocyte fusion (Varner, 2008). Several environmental factors including industrial chemicals, heat, air pollution or smoking can cause disturbances in the chromatin integrity of spermatozoa (Evenson and Wixon, 2005). Toxic heavy metals such as lead, copper or nickel can have a direct or mediated effect on sperm DNA integrity through an interaction with the P2 protamine, while other contaminants like pesticides also have the potential to alter the structure of sperm chromatin (Oliva, 2006).

The aim of the present study was to apply the flow cytometric OxyDNA test to determine the level of oxidative DNA damage in fish spermatozoa exposed to different concentrations of cadmium. The OxyDNA test has not been used to study fish sperm quality so far (Cabrita et al., 2014). The heavy metal cadmium binds to organic matter in water and accumulates in sediments, and it can act as an Endocrine Disrupting Chemical (EDC; Gregory et al., 2008). In our previous study (Kakasi et al., 2013) we determined the $\mathrm{LC}_{50}$ values of cadmium on European perch (Perca fluviatilis) fingerlings. In the present follow-up pilot study our aim was to detect the direct effect of cadmium on sperm DNA, since fish - being external fertilising taxa - release sperm into the water, and there is a possibility that during the time course of fertilisation cadmium contamination induces subcellular damage.

\section{Materials and methods}

Milt was collected from three randomly selected Prussian carp (Carassius auratus gibelio) males via abdominal massage. Sperm release was induced with carp hypophysis solution and anaesthesia with clove oil.

Sperm was transferred to the laboratory immediately after stripping and pooled in order to reduce the effects caused by individual variance (Sood et al., 2012). Sperm concentration was measured with a Minitube SDM 1 photometer and adjusted to approximately $2 \times 10^{6} / \mathrm{mL}$ in phosphate buffered saline (PBS) (P4417, Sigma-Aldrich).

To test the toxic effect of cadmium on spermatozoa we applied the approach of Hoornstra et al. (2003) with modifications. Cadmium chloride (anhydrous $99.99 \%, 11860$, Alfa Aesar) stock solution was prepared at the concentration of $1 \mathrm{mg} / \mathrm{mL}$ in distilled water. Serial dilutions $(10 \times)$ in methanol (01528-10-65, Reanal) were prepared $(0.01-10,000 \mathrm{mg} / \mathrm{L})$. Two-mL aliquots of fish sperm were exposed to $200 \mu \mathrm{L}$ of the serial dilutions, and control samples received $200 \mu \mathrm{L}$ methanol only. The exposure time was $30 \mathrm{~min}$, and sperm aliquots were kept at room temperature in the dark. 
Oxidative DNA damage was assessed with the OxyDNA kit commercially available from Merck (500095 OxyDNA Assay Kit, Fluorometric) and flow cytometry. We followed the protocol applied for bovine sperm by Silva et al. (2007) with modifications. Briefly, cells were fixed in $1 \%$ paraformaldehyde $(97 \%$, A11313, Alfa Aesar) in PBS for $1 \mathrm{~h}$ at room temperature. After washing $(400 \times g$, $10 \mathrm{~min}$ ) in PBS, the cells were permeabilised in $0.1 \%$ Triton-X (Reagent grade, 786-513, G Biosciences) for $15 \mathrm{~min}$ at room temperature. Suspensions were washed $(400 \times g, 10 \mathrm{~min})$ in the washing solution provided in the OxyDNA kit. One hundred $\mu \mathrm{L}$ FITC conjugate was added to the cell pellet and incubated for $1 \mathrm{~h}$ at room temperature in the dark. Suspensions were washed again $(400 \times g, 10 \mathrm{~min})$ in the washing solution, the pellet was resuspended in $1 \mathrm{~mL}$ PBS and subsequently measured with a Beckman Coulter FC 500 flow cytometer equipped with a $488 \mathrm{~nm}$ $20 \mathrm{~mW}$ Ar ion laser. Fluorescence intensity of the FITC conjugate was collected with the FL 1 ( $525 \mathrm{~nm} \mathrm{BP}$ ) detector in linear mode. Spermatozoa and debris were distinguished based on light scatter properties. Five thousand sperm events were recorded per sample. Acquisition files were stored as list mode (LMD) files.

List mode files were analysed with Cyflogic analysis software (Version 1.2.1, www.cyflogic.com). Oxidative DNA damage was indicated as an increase in the green fluorescence intensity of the FITC conjugate (Fig. 1).

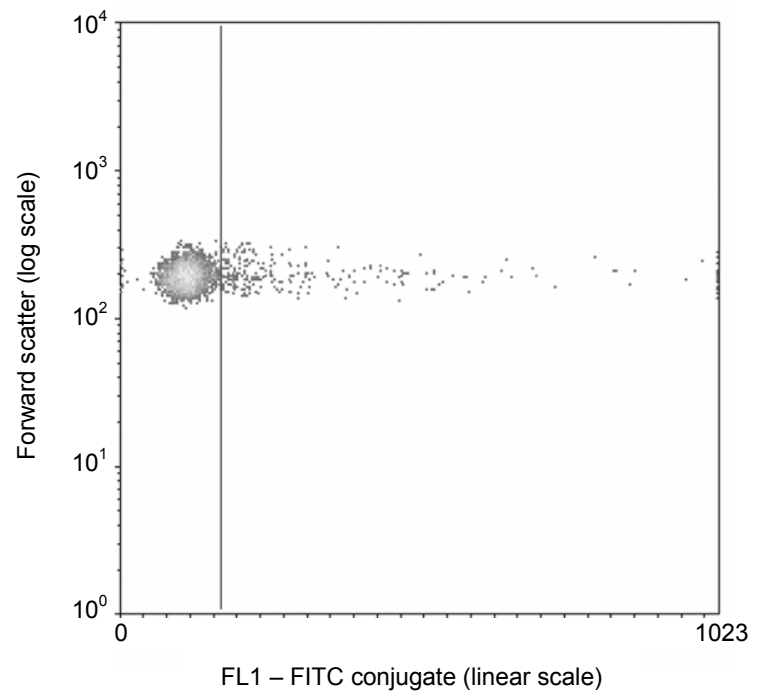

Fig. 1. Density plot showing OxyDNA FITC conjugate fluorescence. Vertical line separates OxyDNA-negative and -positive events

The proportions of OxyDNA-positive events at different cadmium exposures were compared to the methanol control with the nonparametric Yates- 
corrected chi-square test using Statistica data analysis software system (StatSoft, Inc., 2007, version 8.0, www.statsoft.com).

\section{Results}

The ratios of OxyDNA-positive events increased significantly at higher cadmium concentrations. The percentages of the positive events were $6.09 \%$ in the methanol control sample and 6.09, 8.08, 10.03, 10.31, 10.94, 11.18 and $12.45 \%$ in the sperm aliquots exposed to $0.01,0.1,1,10,1000$ and $10,000 \mathrm{mg} / \mathrm{L}$ cadmium, respectively.

Yates-corrected chi-square test indicated that with the exception of the lowest cadmium concentration $(0.01 \mathrm{mg} / \mathrm{L} ; \mathrm{P}=0.994)$ the percentages of OxyDNA positive events were significantly different from the control $(\mathrm{P}<$ 0.0001).

\section{Discussion}

The results of this pilot study indicate that the direct contact of fish spermatozoa with cadmium-polluted water may initiate genotoxic damage. The importance of sperm DNA damage from the point of view of fertilisation outcome is already well known (Evenson, 1999). The oxidative DNA damage detected in the present study may be due to cytotoxic effects - the main sources of reactive oxygen species (ROS) in spermatozoa are the defective mitochondria (Aitken et al., 2012). Oxidative DNA damage induces abasic sites, which may lead to single and double strand breaks in the sperm DNA (De Iuliis et al., 2009; Aitken et al., 2012). Even a rather low rate of DNA damage in spermatozoa may result in subor infertility: threshold values for subfertility due to sperm DNA fragmentation as measured by the Sperm Chromatin Structure Assay (SCSA) were 30\% for human, $10-20 \%$ for bull and $8 \%$ for boar spermatozoa (Evenson and Wixon, 2006). To the best of our knowledge there are no similar threshold values for fish sperm available in the literature. In our opinion the results of this pilot study will be useful in designing larger-scale experiments to test the cytotoxic and genotoxic effects of cadmium (and other EDCs) on the fertilising ability of fish spermatozoa and the embryonic development of fertilised fish oocytes. Our preliminary results show the usefulness of flow cytometry to detect intracellular and sublethal sperm damage in fish exposed to contaminated water and may be directly useful for aquaculture managers as well as researchers who plan ecotoxicology studies on the reproductive success of fish in polluted environments. 


\section{Acknowledgements}

Dr. Sz. Nagy was supported by the European Union and the State of Hungary, cofinanced by the European Social Fund in the framework of TÁMOP-4.2.4.A/2-11/12012-0001 'National Excellence Programme'.

\section{References}

Aitken, R. J., De Iuliis, G. N., Gibb, Z. and Baker, M. A. (2012): The Simmet lecture: new horizons on an old landscape - oxidative stress, DNA damage and apoptosis in the male germ line. Reprod. Dom. Anim. 47 (Suppl. 4), 7-14.

Cabrita, E., Martínez-Páramo, S., Gavaia, P. J., Riesco, M. F., Valcarce, D. G., Sarasquete, C., Herráez, M. P. and Robles, V. (2014): Factors enhancing fish sperm quality and emerging tools for sperm analysis. Aquaculture 432, 389-401.

Dadoune, J. P. (1995): The nuclear status of human sperm cells. Micron 26, 323-345.

De Iuliis, G. N., Thomson, L. K., Mitchell, L. A., Finnie, J. M., Koppers, A. J., Hedges, A., Nixon, B. and Aitken, R. J. (2009): DNA damage in human spermatozoa is highly correlated with the efficiency of chromatin remodeling and the formation of 8-hydroxy-2'-deoxyguanosine, a marker of oxidative stress. Biol. Reprod. 81, 517-524.

Evenson, D. P. (1999): Loss of livestock breeding efficiency due to uncompensable sperm nuclear defects. Reprod. Fertil. Dev. 11, 1-15.

Evenson, D. P. and Wixon, R. (2005): Environmental toxicants cause sperm DNA fragmentation as detected by the Sperm Chromatin Structure Assay (SCSA). Toxicol. Appl. Pharmacol. 207, 532-537.

Evenson, D. P. and Wixon, R. (2006): Clinical aspects of sperm DNA fragmentation detection and male infertility. Theriogenology 65, 979-991.

Gregory, M., Aravindakshan, J., Nadialek, S. and Cyr, D. G. (2008): Effects of endocrine disrupting chemicals on testicular functions. In: Alavi, S. M. H., Cosson, J. J., Coward, K. and Rafiee, G. (eds) Fish Spermatology. Alpha Science International Ltd., Oxford, UK. pp. 161-214.

Hoornstra, D., Andersson, M. A., Mikkola, R. and Salkinoja-Salonen, M. S. (2003): A new method for in vitro detection of microbially produced mitochondrial toxins. Toxicology in Vitro 17, 745-751.

Kakasi, B., Balikó, T., Bercsényi, M., Merth, J. and Nagy, Sz. T. (2013): Determination of the LC50 value of cadmium in European perch (Perca fluviatilis) fingerlings [in Hungarian]. Proceedings of 50th Georgikon Scientific Conference, Keszthely, Hungary. p. 58.

Oliva, R. (2006): Protamines and male infertility. Hum. Reprod. Update 12, 417-435.

Olsen, A. K., Lindeman, B., Wiger, R., Duale, N. and Brunborg, G. (2005): How do male germ cells handle DNA damage? Toxicol. Appl. Pharmacol. 207, 521-531.

Sakkas, D., Mariethoz, E., Manicardi, G., Bizzaro, D., Bianchi, P. G. and Bianchi, U. (1999): Origin of DNA damage in ejaculated human spermatozoa. Rev. Reprod. 4, 31-37.

Silva, P. F., Gadella, B. M., Colenbrander, B. and Roelen, B. A. (2007): Exposure of bovine sperm to pro-oxidants impairs the developmental competence of the embryo after the first cleavage. Theriogenology 67, 609-619.

Sood, S., Malecki, I. A., Tawang, A. and Martin, G. B. (2012): Survival of emu (Dromaius novaehollandiae) sperm preserved at subzero temperatures and different cryoprotectant concentrations. Theriogenology 78, 1557-1569.

Varner, D. D. (2008): Developments in stallion semen evaluation. Theriogenology 70, 448-462. 